\title{
A Gene Cluster Involved in Metal Homeostasis in the Cyanobacterium Synechocystis sp. Strain PCC 6803
}

\author{
MARIO GARCÍA-DOMÍNGUEZ, LUIS LOPEZ-MAURY, FRANCISCO J. FLORENCIO, AND JOSÉ C. REYES* \\ Instituto de Bioquímica Vegetal y Fotosíntesis, Universidad de Sevilla-CSIC, E-41092 Sevilla, Spain
}

Received 18 October 1999/Accepted 14 December 1999

\begin{abstract}
A gene cluster composed of nine open reading frames (ORFs) involved in $\mathrm{Ni}^{2+}, \mathrm{Co}^{2+}$, and $\mathrm{Zn}^{2+}$ sensing and tolerance in the cyanobacterium Synechocystis sp. strain PCC 6803 has been identified. The cluster includes an $\mathrm{Ni}^{2+}$ response operon and a $\mathrm{Co}^{2+}$ response system, as well as a $\mathrm{Zn}^{2+}$ response system previously described. Expression of the $\mathrm{Ni}^{2+}$ response operon (nrs) was induced in the presence of $\mathrm{Ni}^{2+}$ and $\mathrm{Co}^{2+}$. $\mathrm{Reduced}^{2+}$ tolerance was observed following disruption of two ORFs of the operon (nrs $A$ and $n r s D$ ). We also show that the $n r s D$ gene encodes a putative $\mathrm{Ni}^{2+}$ permease whose carboxy-terminal region is a metal binding domain. The $\mathrm{Co}^{2+}$ response system is composed of two divergently transcribed genes, $\operatorname{cor} R$ and $\operatorname{corT}$, mutants of which showed decreased $\mathrm{Co}^{2+}$ tolerance. Additionally, corR mutants showed an absence of $\mathrm{Co}^{2+}$-dependent induction of $\operatorname{cor} T$, indicating that CorR is a transcriptional activator of $\operatorname{cor} T$. To our knowledge, CorR is the first $\mathrm{Co}^{2+}$-sensing transcription factor described. Our data suggest that this region of the Synechocystis sp. strain PCC 6803 genome is involved in sensing and homeostasis of $\mathrm{Ni}^{2+}, \mathrm{Co}^{2+}$, and $\mathrm{Zn}^{2+}$.
\end{abstract}

At above critical concentrations, essential transition metal ions such as $\mathrm{Ni}^{2+}, \mathrm{Co}^{2+}$, and $\mathrm{Zn}^{2+}$ are toxic, being, for example, potent inhibitors of processes such as respiration and photosynthesis (see, for example, references 4, 22, 28, and 39). In addition, transition metals are required for the catalytic activity of a number of enzymes because of their redox activity and their high charge density, which allows the polarization of substrates and the stabilization of transition state intermediates. Bacteria have evolved sensing, sequestering, and transport systems that allow a precise homeostasis for these metals.

During the last years it has became clear that microbial $\mathrm{Ni}^{2+}, \mathrm{Zn}^{2+}$, and $\mathrm{Co}^{2+}$ uptake is mediated by nonspecific transport systems for divalent cations (33) and by high-affinity specific systems. Two types of high-affinity transporters have been identified: (i) multicomponent ATP-binding cassette transport systems (such as NikABCDE for $\mathrm{Ni}^{2+}$ or $\mathrm{ZnuABC}$ for $\mathrm{Zn}^{2+}$ ) $(31,37)$ and (ii) one-component transporters (such as NixA, UreH, HupN, and HoxN for $\mathrm{Ni}^{2+}$ and NhlF for $\left.\mathrm{Co}^{2+}\right)(12,16$, $23,27,29)$ which are integral membrane proteins with eight transmembrane-spanning helices.

Most of the studies on $\mathrm{Co}^{2+}, \mathrm{Zn}^{2+}$, and $\mathrm{Ni}^{2+}$ export and resistance have been carried out with the soil chemolithotrophic Alcaligenes strains (now designed Ralstonia), where three sequence-related divalent cation efflux operons, called $c z c$ (for $\mathrm{Cd}^{2+}, \mathrm{Zn}^{2+}$, and $\mathrm{Co}^{2+}$ resistance) (32), chr (for $\mathrm{Co}^{2+}$ and $\mathrm{Ni}^{2+}$ resistance) (25), and $n c c$ (for $\mathrm{Ni}^{2+}, \mathrm{Co}^{2+}$, and $\mathrm{Cd}^{2+}$ resistance) (47), have been described. $\mathrm{Zn}^{2+}$-dependent efflux ATPases have been recently characterized for Escherichia coli (zntA) (3) and for the cyanobacterium Synechocystis sp. strain PCC 6803 (ziaA) (51). ZntA and ZiaA belong to the P-type ATPase family (recently reviewed in reference 40 ), which includes the bacterial $\mathrm{Cd}^{2+}$ transporter CadA (34) and bacterial $\mathrm{Cu}^{2+}$ transporters $(20,35,38)$.

Much less is known about how $\mathrm{Ni}^{2+}, \mathrm{Zn}^{2+}$, and $\mathrm{Co}^{2+}$ are sensed and how metal binding provokes protein conformational changes that determine regulatory responses. Two types

\footnotetext{
* Corresponding author. Mailing address: Instituto de Bioquímica Vegetal y Fotosíntesis, Centro de Investigaciones Científicas Isla de la Cartuja, C/. Américo Vespucio s/n, 41092 Sevilla, Spain. Phone: 34 954489518. Fax: 34 954460065. E-mail: jcreyes@cica.es.
}

of $\mathrm{Zn}^{2+}$-responsive regulators have been recently described. $\mathrm{ZntR}$ is a MerR-like transcriptional activator of $z n t A$ expression in E. coli (7). In contrast, Synechococcus sp. strain PCC 7942 SmtB (19), Synechocystis sp. strain PCC 6803 ZiaR (51), and Staphylococcus aureus ZntR (49) are transcriptional repressors that belong to the ArsR-SmtA family of helix-turnhelix DNA binding proteins. Although the overall ternary structure for these repressors is conserved, the metal binding site may be unique for each specific member of the family (9). Regulation of the $c z c$ efflux operon of Ralstonia eutropha is currently under active study, and at least three proteins, CzcD, $\mathrm{CzcR}$, and $\mathrm{CzcS}$, seem to be involved in metal sensing (55). The only nickel-specific responsive regulator reported is NikR, a Fur-related DNA binding protein that represses the transcription of the E. coli nikABCDE operon in the presence of high $\mathrm{Ni}^{2+}$ concentrations (11). Finally, no $\mathrm{Co}^{2+}$-specific sensor proteins have been reported so far.

We report in the present work the identification and characterization of a metal-regulated gene cluster in the unicellular cyanobacterium Synechocystis sp. strain PCC 6803. The cluster comprises nine open reading frames (ORFs) organized into five transcriptional units and seems to be responsible for $\mathrm{Ni}^{2+}$, $\mathrm{Co}^{2+}$, and $\mathrm{Zn}^{2+}$ homeostasis in Synechocystis sp. strain PCC 6803 .

\section{MATERIALS AND METHODS}

Strains and growth conditions. Synechocystis sp. strain PCC 6803 was grown photoautotrophically at $30^{\circ} \mathrm{C}$ in BG11 medium (43) supplemented with $1 \mathrm{~g}$ of $\mathrm{NaHCO}_{3}$ per liter (BG11C) and bubbled with a continuous stream of $1 \%(\mathrm{vol} /$ vol) $\mathrm{CO}_{2}$ in air under continuous illumination $\left(50 \mu \mathrm{mol}\right.$ of photons per $\mathrm{m}^{2}$ per $\mathrm{s}$; white light from fluorescent lamps). For plate cultures, BG11C liquid medium was supplemented with $1 \%$ (wt/vol) agar. Kanamycin was added to a final concentration of 50 to $200 \mu \mathrm{g} / \mathrm{ml}$ when required. BG11C medium was supplemented with different concentrations of $\mathrm{ZnSO}_{4}, \mathrm{CdCl}_{2}, \mathrm{CoCl}_{2}, \mathrm{CuSO}_{4}, \mathrm{NiSO}_{4}$, and $\mathrm{MgCl}_{2}$ when indicated.

E. coli DH5 $\alpha$ (Bethesda Research Laboratories) grown in Luria broth medium as described previously (46) was used for plasmid construction and replication. E. coli BL21 grown in Luria broth medium supplemented with $2 \%$ glucose was used for expression of glutathione $S$-transferase (GST)-C-NrsD or GST proteins. E. coli strains were supplemented with $100 \mu \mathrm{g}$ of ampicillin per $\mathrm{ml}$ when required.

Insertional mutagenesis of Synechocystis sp. strain PCC 6803 genes. Loci slr0794, slr0796, slr0797, and sll0794 were inactivated by interruption with a kanamycin resistance cassette (C.K1) (14). For this, DNA fragments containing 
TABLE 1. Oligonucleotides used in this work

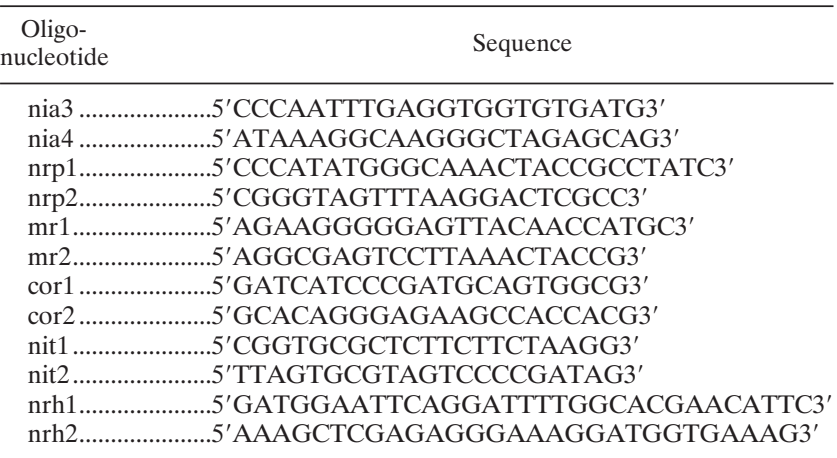

loci slr0794, slr0796, slr0797, and sl10794 were amplified by PCR from the cosmid CS1377 (provided by Kazusa DNA Research Institute) and cloned into pGEM-T (Promega). slr0794 was amplified by using oligonucleotides nit1 and nit2 (Table 1) and cloned into pGEM-T to generate pNIQ7. Targeting vectors were generated by inserting the C.K1 cassette into the EcoRI site of slr0794 in the same orientation as the $n r s$ operon [pNIQ8(+)] or in the inverse orientation [pNIQ8(-)]. slr0796 was amplified by using oligonucleotides nrp1 and nrp2 (Table 1) and cloned into pGEM-T to generate pNIQ1. Targeting vectors were generated by inserting the C.K1 cassette into the BstEII site of slr0796 in the same orientation as the $n r s$ operon [pNIQ2 $(+)]$ or in the inverse orientation [pNIQ2(-)]. slr0797 was amplified by using oligonucleotides cor1 and cor2 (Table 1) and cloned into pGEM-T to generate pNIQ10. The targeting vector was generated by inserting the C.K1 cassette into the EcoNI site of slr0797 in the opposite orientation to the slr0797 gene (pNIQ12). sll0794 was amplified by using oligonucleotides $\mathrm{mr} 1$ and $\mathrm{mr} 2$ (Table 1 ) and cloned into pGEM-T to generate pNIQ3. The targeting vector was generated by inserting the C.K1 cassette into the HindIII site of sll0794 in the same orientation as the sllo794 ORF [pNIQ4(+)]. All targeting vectors were used to transform Synechocystis sp. strain PCC 6803 strain as previously described (15).

Correct integration and complete segregation of the mutant strains were tested by Southern blotting. For this, total DNA from cyanobacteria was isolated as previously described (8). DNA was digested and electrophoresed in $0.7 \%$ agarose gels in a Tris-borate-EDTA buffer system (46), and then DNA was transferred to nylon Z-probe membranes (Bio-Rad, Hercules, Calif.). DNA probes were ${ }^{32} \mathrm{P}$ labeled with a random-primer kit (Pharmacia, Uppsala, Sweden) using $\left[\alpha{ }^{-32} \mathrm{P}\right] \mathrm{dCTP}(3,000 \mathrm{Ci} / \mathrm{mmol})$.

RNA isolation and Northern blot hybridization. Total RNA was isolated from 25-ml samples of Synechocystis sp. strain PCC 6803 cultures at the mid-exponential growth phase ( 3 to $5 \mu \mathrm{g}$ of chlorophyll/ml). Extractions were performed by vortexing cells in the presence of phenol-chloroform and acid-washed baked glass beads ( 0.25 - to 0.3 -mm diameter; Braun, Melsungen, Germany) as previously described (17).

For Northern blot analyses, $15 \mu \mathrm{g}$ of total RNA was loaded per lane and electrophoresed in $1.2 \%$ agarose denaturing formaldehyde gels. Transfer to nylon membranes (Hybond N-Plus; Amersham), prehybridization, hybridization, and washes were in accordance with Amersham instruction manuals. Probes for Northern blot hybridization were PCR synthesized using the following oligonucleotides pairs: nia3-nia4, probe a; nrp1-nrp2, probe $\mathbf{b} ; \mathrm{mr} 1-\mathrm{mr} 2$, probe $\mathbf{c}$; and cor1-cor2, probe $\mathbf{d}$ (Table 1). DNA probes were ${ }^{32} \mathrm{P}$ labeled with a randomprimer kit (Pharmacia) using $\left[\alpha{ }^{-32} \mathrm{P}\right] \mathrm{dCTP}(3,000 \mathrm{Ci} / \mathrm{mmol})$. All of the filters were stripped and reprobed with a HindIII-Bam HI 580-bp probe from plasmid pAV1100 that contains the constitutively expressed RNase P RNA gene (rnpB) from Synechocystis sp. strain PCC 6803 (56). To determine counts per minute of radioactive areas in Northern blot hybridizations, an InstantImager Electronic Autoradiography apparatus (Packard Instrument Company, Meriden, Conn.) was used.

Purification of GST-C-NrsD and metal affinity chromatography. The last 126 bp of the $n r s D$ ORF, which encodes the last 42 amino acids of NrsD, was amplified by PCR using the oligonucleotides nrh1 and nrh2 (Table 1). The resulting DNA fragment was digested with EcoRI and $X h o \mathrm{I}$ and cloned into pGEX-4T-3 in phase with the GST gene to generate pGEX-C-NrsD. GST-CNrsD fusion protein and GST were expressed in E. coli BL21 from the plasmids pGEX-C-NrsD and pGEX-4T-3, respectively. One liter of culture was grown in Luria broth medium supplemented with $2 \%$ glucose to an optical density at 600 $\mathrm{nm}$ of 0.6 , induced with $1 \mathrm{mM}$ isopropyl- $\beta$-D-thiogalactopyranoside for $2.5 \mathrm{~h}$, harvested by centrifugation, and resuspended in $20 \mathrm{ml}$ of phosphate-buffered saline buffer $\left(150 \mathrm{mM} \mathrm{NaCl}, 16 \mathrm{mM} \mathrm{Na}_{2} \mathrm{HPO}_{4}, 4 \mathrm{mM} \mathrm{NaH} \mathrm{PO}_{4}, \mathrm{pH} 7.2\right)$ supplemented with $1 \mathrm{mM}$ phenylmethylsulfonyl fluoride. Cells were broken by sonication, and insoluble debris was pelleted by centrifugation at $18,000 \times g$ for $15 \mathrm{~min}$. The supernatant was then applied to a glutathione-agarose bead column (Pharmacia) (1-ml bed volume). After extensive washing with phosphate-buff- ered saline buffer, GST or GST-C-NrsD proteins were eluted with $3 \mathrm{ml}$ of 50 $\mathrm{mM}$ Tris $\mathrm{HCl}(\mathrm{pH} 8.0)$ containing $10 \mathrm{mM}$ reduced glutathione. Glutathione was then removed by gel filtration in a Sephadex G-25 column. Interaction of GSTC-NrsD or GST with $\mathrm{Ni}^{2+}, \mathrm{Co}^{2+}, \mathrm{Zn}^{2+}, \mathrm{Cu}^{2+}$, or $\mathrm{Mg}^{2+}$ was investigated by metal ion affinity chromatography. A 0.5 -ml portion of His-bind resin (Novagen) was loaded with $0.5 \mathrm{ml}$ of $0.5 \mathrm{M} \mathrm{ZnSO}_{4}, \mathrm{CoCl}_{2}, \mathrm{CuSO}_{4}, \mathrm{NiSO}_{4}$, or $\mathrm{MgCl}_{2}$ in water and then equilibrated in $0.5 \mathrm{M}$ sodium chloride $-50 \mathrm{mM}$ Tris $\mathrm{HCl}(\mathrm{pH} 8.0)$ (buffer A). About $30 \mu \mathrm{g}$ of purified GST-C-NrsD or GST proteins were applied to the columns. Unbound proteins were removed by washing with buffer A. Bound polypeptides were eluted with $0.5 \mathrm{ml}$ of $0.4 \mathrm{M}$ imidazole in buffer A. Proteins were then analyzed by sodium dodecyl sulfate-polyacrylamide gel electrophoresis (SDS-PAGE) (24) and Coomassie blue staining. Quantities of bound and unbound proteins were determined by the method of Bradford (5).

Computer methods. The BLAST program (1) was used to screen the translated nucleotides databases. The CLUSTAL X program was used to generate sequence alignments (53). Putative membrane-spanning regions were identify using different algorithms $(18,57)$.

\section{RESULTS AND DISCUSSION}

A metal-regulated gene cluster in Synechocystis sp. strain PCC 6803. Analysis of the fully sequenced Synechocystis sp. strain PCC 6803 genome (21) allowed us to identify a region of the chromosome containing three ORFs whose deduced amino acid sequences are clearly related to metal transport proteins (see below). The region extends $12 \mathrm{~kb}$ and comprises nine genes organized into five putative transcription units (Fig. 1A). ORF slr0798 has been reported to encode a $\mathrm{Zn}^{2+}$-dependent efflux ATPase (ZiaA) whose expression is $\mathrm{Zn}^{2+}$ dependent (51). A putative operon composed of two ORFs, sll0793 and sll0792, separated by $11 \mathrm{bp}$ appears upstream from the ziaA gene and in the opposite orientation. sll0792 encodes $\mathrm{ZiaR}$, the transcriptional repressor of ziaA. sll0793 is a putative membrane protein that does not share significant homology with any other protein in the EMBL-GenBank database (51). Metal-dependent expression of the remaining three putative transcriptional units was analyzed by Northern blotting. For this, four probes were used to hybridize total RNA obtained from mid-log-phase Synechocystis sp. strain PCC 6803 cells grown in BG11C medium and exposed during $1 \mathrm{~h}$ to a $15 \mu \mathrm{M}$ concentration of either $\mathrm{ZnSO}_{4}, \mathrm{CdCl}_{2}, \mathrm{CoCl}_{2}, \mathrm{CuSO}_{4}, \mathrm{NiSO}_{4}$, or $\mathrm{MgCl}_{2}$ (Fig. 1B). Control cells were not exposed to added metals. Probes a (internal to slr0793) and b (internal to slr0796) hybridized strongly with RNA obtained from $\mathrm{Ni}^{2+}$. exposed Synechocystis sp. strain PCC 6803 cells and weakly with RNA from $\mathrm{Co}^{2+}$-exposed cells. Probe c (ORF sll0794) showed no hybridization with RNA from any of the conditions tested. Probe d, corresponding to ORF slr0797, hybridized strongly with RNA from $\mathrm{Co}^{2+}$-exposed cells and weakly with RNA from $\mathrm{Zn}^{2+}$-exposed cells. Transcript levels of the RNase P RNA (rnpB gene) (56) remained unchanged under all tested conditions (Fig. 1B).

These results demonstrate the metal-dependent expression of two of the transcription units of the region. These data, together with the results of Thelwell et al. (51) about ziaA and ziaR genes, allow us to define the existence of a metal-regulated gene cluster in Synechocystis sp. strain PCC 6803.

nrs is a nickel resistance operon. As shown above, a similar pattern of induction was found using probes from ORFs slr0793, and slr0796 (Fig. 1B). The fact that both probes hybridized with RNA of about $6 \mathrm{~kb}$, together with the structure of the region, suggests that ORFs slr0793, slr0794, slr0795, and slr0796 form a transcriptional unit. Since $\mathrm{Ni}^{2+}$ provoked the highest induction of this transcription unit, the genes were named $n r s$ for $\mathrm{Ni}^{2+}$ response system. The $n r s$ induction dependence on concentration was studied by using Northern blot experiments. The operon was induced at $\mathrm{Ni}^{2+}$ concentrations of above $0.45 \mu \mathrm{M}$. An $\mathrm{Ni}^{2+}$ concentration of above $17 \mu \mathrm{M}$ did not provoke higher accumulation of the $n r s$ mRNA (Fig. $2 \mathrm{~A}$ 


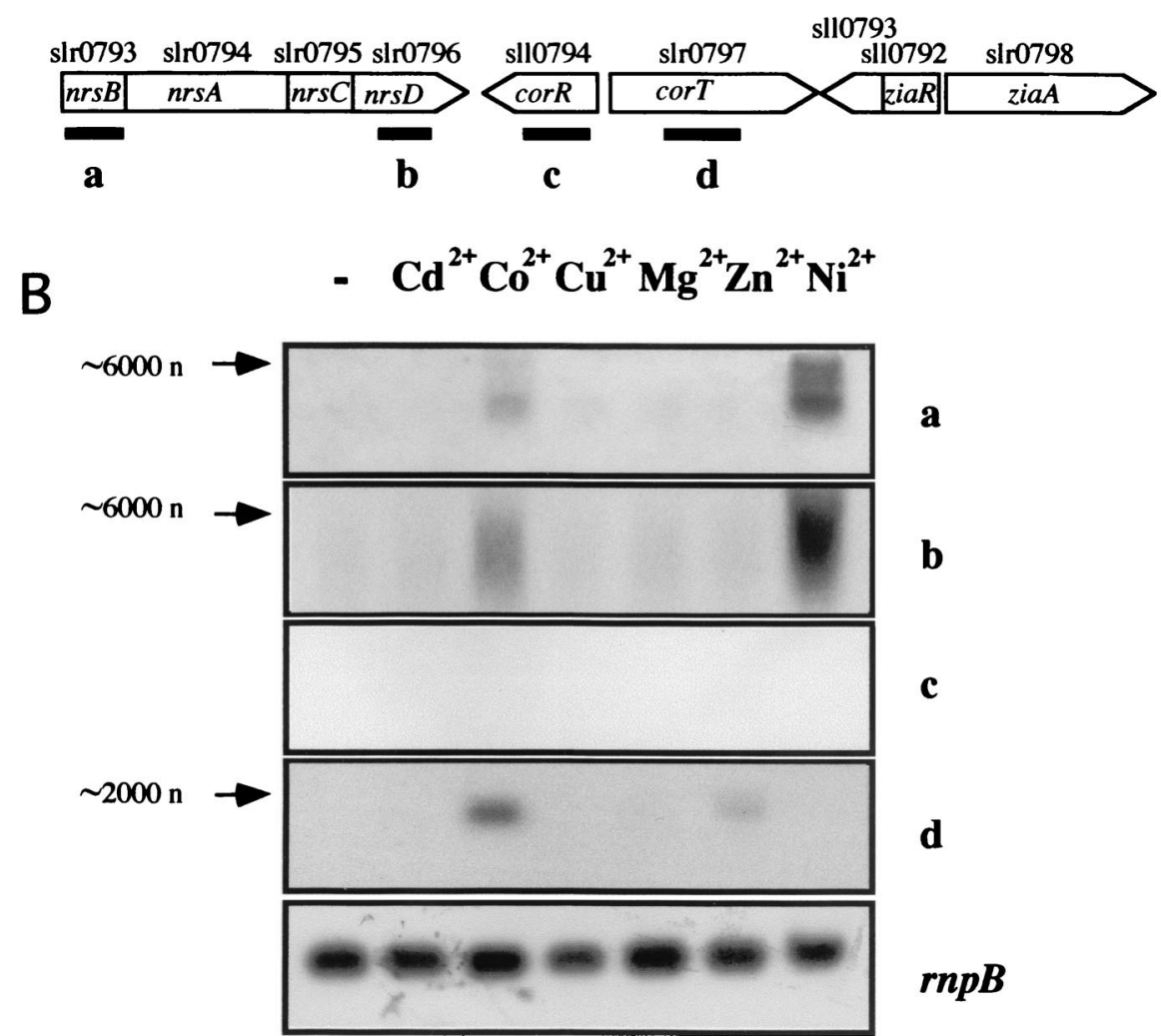

FIG. 1. Metal-dependent expression of the Synechocystis transition metal-resistant cluster. (A) ORF organization of the metal-regulated cluster from Synechocystis sp. strain PCC 6803. (B) Total RNA was isolated from mid-log-phase Synechocystis sp. strain PCC 6803 cells exposed for $1 \mathrm{~h}$ to a $15 \mu \mathrm{M}$ concentration of the indicated metal ions. Control cells were not exposed to added metals (-). Fifteen micrograms of total RNA was denatured, separated by electrophoresis in a $1.2 \%$ agarose gel, blotted, and hybridized with probes a to d as indicated in panel A (see Materials and Methods). The filters were stripped and rehybridized with an $r n p B$ gene probe as a control. Estimated sizes of the transcripts (in nucleotides [n]) are indicated.

and data not shown). Time course analysis indicated that $n r s$ mRNA was already induced 15 min after metal addition and increased almost linearly, at least during the first $4 \mathrm{~h}$ of treatment (Fig. 2B and C).

In order to get information about the function of $n r s$ genes, we have analyzed their deduced amino acid sequences. The ORF slr0793 (nrsB) and slr0794 (nrs $A$ ) products showed clear sequence similarity with the $R$. eutropha $c z c B$ and $c z c A$ gene products, respectively (32). While NrsA displays $35 \%$ identity and $55 \%$ similarity with $\mathrm{CzcA}$ throughout the entire amino acid sequence, $\mathrm{NrsB}$ and $\mathrm{CzcB}$ show significant similarity $(34 \%$ identity and $45 \%$ similarity) only in a central 80 -amino-acid region (from amino acid 54 to 132 of the NrsB sequence). The $c z c A B C$ gene products form a membrane-bound protein complex catalyzing $\mathrm{Co}^{2+}, \mathrm{Zn}^{2+}$, and $\mathrm{Cd}^{2+}$ efflux by a proton/cation antiporter in $R$. eutropha. CzcA is thought to be the inner membrane protein responsible for the efflux activity (48). CzcB is a periplasmic protein probably involved in membrane fusion that bridges the inner and the outer cell membranes of gramnegative bacteria (41). The protein encoded by ORF slr0795 (nrsC) is not homologous to proteins encoded by the $c z c$ or related operons. Interestingly, the $\mathrm{NrsC}$ carboxy-terminal (Cterminal) region shares significant similarity (26 to $30 \%$ identity in about 140 amino acids) with Neisseria gonorrhoeae autolysin A and bacteriophage-encoded lysozymes. In addition, computer analysis of the $\mathrm{NrsC}$ sequence indicated the exis- tence of two putative transmembrane helices in the aminoterminal region of the protein (amino acids 24 to 47 and 70 to 89 from the NrsC sequence). Finally, the slr0796 (nrsD) product is a 445-amino-acid protein which shows significant amino acid sequence identity to the $n r e B$ gene product. The nre locus was identified as a low-level $\mathrm{Ni}^{2+}$ resistance determinant in Alcaligenes xylosoxidans 31A (47), different from the high-level $\mathrm{Ni}^{2+}$ resistance determinant (ncc) homologous to the $c z c$ system.

The homologies displayed by the Nrs proteins together with the pattern of expression of their genes suggested that the Nrs system is involved in $\mathrm{Ni}^{2+}$ and $\mathrm{Co}^{2+}$ tolerance in Synechocystis sp. strain PCC 6803. In order to verify this hypothesis, two different $n r s$ mutants were generated by insertion of kanamycin resistance cassettes (C.K1) (14) into the $n r s A$ and $n r s D$ genes (Fig. 3A). In order to abolish polar effects, C.K1 cassettes were inserted in both orientations. Since the C.K1 cassette is lacking a transcription terminator (J. C. Reyes, unpublished observation), insertional mutagenesis in the same orientation as the $n r s$ operon does not suppress transcription of the genes downstream of the insertion point. Similar results were obtained for both orientations, and therefore only mutants with the $n p t$ gene in the same orientation as the $n r s$ genes are shown. $n r s A:$ C.K1 and nrsD::C.K1 Synechocystis strains were viable, and their growth rates in BG11C medium were comparable to those of the wild-type strain (data not shown). Growth of 
A

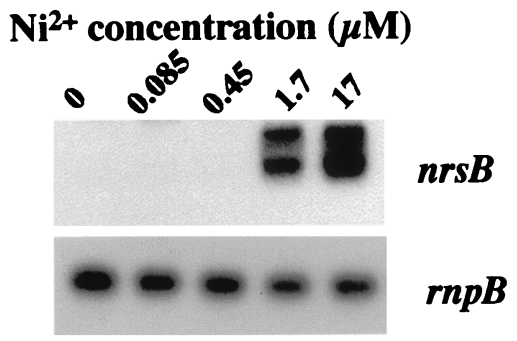

B Time (min) $\begin{array}{llllll}0 & 15 & 30 & 60 & 120 & 240\end{array}$

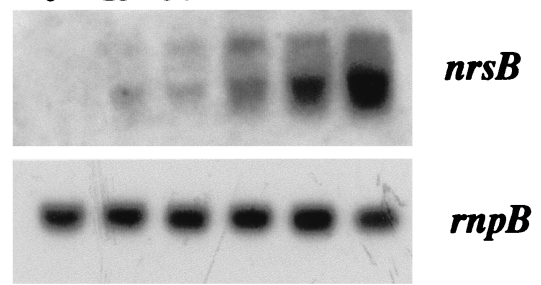

C

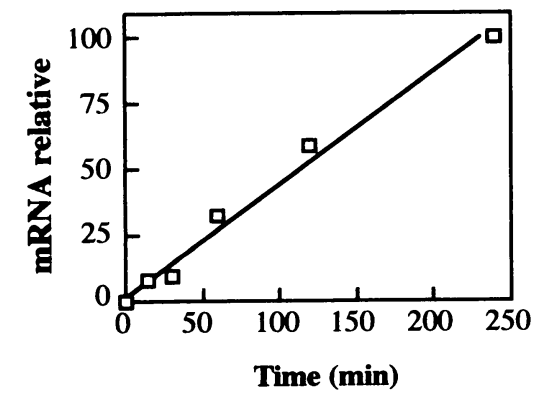

FIG. 2. $\mathrm{Ni}^{2+}$ concentration dependence and time course of the expression of nrs. (A) The indicated concentration of $\mathrm{NiSO}_{4}$ was added to mid-log-phase Synechocystis sp. strain PCC 6803 cells grown in BG11C medium. After 1 h, cells were harvested and total RNA was isolated, processed, and hybridized as described for Fig. 1, using an $n r s B$ gene probe (probe a [Fig. 1]). (B) A $17 \mu \mathrm{M}$ concentration of $\mathrm{NiSO}_{4}$ was added to mid-log-phase Synechocystis sp. strain PCC 6803 cells grown in BG11C medium. Samples for total RNA isolation were taken at the indicated times. RNA was processed and hybridized as for Fig. 1, using an $n r s B$ gene probe. (C) Radioactive signals of the time course experiment were quantified with a InstantImager Electronic Autoradiography apparatus. Levels of $n r s$ operon mRNA were normalized with the $r n p B$ signal, and plots of relative mRNA levels versus time were drawn.

$n r s A:: \mathrm{C} . \mathrm{K} 1$ and $n r s D:: \mathrm{C} . \mathrm{K} 1$ mutants was also examined in $\mathrm{Zn}^{2+}, \mathrm{Ni}^{2+}$-, and $\mathrm{Co}^{2+}$-supplemented BG11C medium. Normal growth was observed in $\mathrm{Zn}^{2+}$ - or $\mathrm{Co}^{2+}$-containing medium (data not shown); however, a reduced tolerance to $\mathrm{Ni}^{2+}$ was clearly observed for both $n r s$ mutants (Fig. 3B). Interestingly the level of $\mathrm{Ni}^{2+}$ tolerance of the $n r s A:$ C.K1 strain was lower than that of the $n r s D:: C . K 1$ strain. While $n r s A:: C . K 1$ mutants were unable to grow in medium containing $7 \mu \mathrm{M} \mathrm{Ni}{ }^{2+}$, $n r s D:: C . K 1$ mutant cells were sensitive only to concentrations of above $12 \mu \mathrm{M} \mathrm{Ni}^{2+}$. These data suggest that NrsD and NrsA might form part of two independent systems for $\mathrm{Ni}^{2+}$ tolerance. This is in good agreement with the data reported for $A$. xylosoxidans, where the ncc and nre loci form two independent systems for $\mathrm{Ni}^{2+}$ resistance (47). Since $n r s B$ - and $n r s A$-homologous genes has been found to be involved in heavy-metal efflux, it seems logical to speculate that the NrsB and NrsA proteins form an $\mathrm{Ni}^{2+}$ efflux system in Synechocystis sp. strain PCC 6803. A difference between the Nrs system from Synechocystis sp. strain PCC 6803 and the Czc system from $R$. eutropha is the lack of a $\mathrm{CzcC}$ homolog in the cyanobacterial $\mathrm{Ni}^{2+}$ response system. Deletion of the $c z c C$ gene results in a loss of $\mathrm{Cd}^{2+}$ and $\mathrm{Co}^{2+}$ resistance, but not $\mathrm{Zn}^{2+}$ resistance, suggesting that $\mathrm{CzcC}$ is involved in substrate specificity but not in the transport activity of the complex (32).

The amino-terminal part of NrsD is a metal binding domain. As previously mentioned, the closest NrsD homolog is the product of the $A$. xylosoxidans nreB gene, which has not been characterized. NrsD shows also very significant sequence similarity to several members of the major facilitator superfamily (MFS) (36). MFS transporters are single polypeptides, containing 12 to 14 transmembrane-spanning regions, capable of transporting small solutes in response to a chemiosmotic gradient. Computer analysis of the NrsD amino acid sequence indicated the existence of 12 putative transmembrane helices distributed along the first 400 amino acids of the protein (Fig. 4A). These data, taken together with the phenotype of the $n r s D$ mutants, suggest that NrsD is a member of the MFS of permeases involved in $\mathrm{Ni}^{2+}$ export. Interestingly, the NrsD protein does not show sequence similarity with a family of well-characterized $\mathrm{Ni}^{2+}$ permeases including $\mathrm{UreH}$, HupN, and HoxN $(12,16,27)$. These proteins show a common topology, with eight membrane-spanning segments. The second transmembrane helix includes a putative $\mathrm{Ni}^{2+}$ binding motif $\left(\mathrm{HX}_{4} \mathrm{DH}\right)$ whose mutation completely abolishes transport activity (13). This motif is not present in the putative transmembrane helices of NrsD. The strongly hydrophilic C-terminal part of NrsD contains a remarkably high number of histidine residues (12 out of 40 amino acids), which are generally considered to be potential metal ligands. In order to test whether this domain of $\mathrm{NrsD}$ is involved in metal binding, a chimeric protein comprising amino acids 403 to 445 of NrsD (C-NrsD) fused to the GST was expressed in E. coli (Fig. 4B). The GST-C-NrsD fusion protein was purified by affinity chromatography on glutathione-agarose. One major band of about 31 $\mathrm{kDa}$ (fusion protein between the GST [26 kDa] and the CNrsD domain [5 kDa]) was visible after SDS-PAGE and Coomassie blue staining. Interaction of GST or GST-C-NrsD with $\mathrm{Ni}^{2+}, \mathrm{Co}^{2+}, \mathrm{Zn}^{2+}, \mathrm{Cu}^{2+}$, and $\mathrm{Mg}^{2+}$ was evaluated by metal affinity chromatography. For this, GST or GST-C-NrsD fusion proteins were loaded into His-bind resin chelating columns charged with the appropriate ions. About $90 \%$ of the GST-C$\mathrm{NrsD}$ fusion protein was retained by the $\mathrm{Ni}^{2+}-, \mathrm{Co}^{2+}-$, and $\mathrm{Cu}^{2+}$-containing columns (Fig. 4C and D). About $60 \%$ of the GST-C-NrsD protein was also retained in the $\mathrm{Zn}^{2+}$-containing column. In contrast, GST-C-NrsD was not retained in the $\mathrm{Mg}^{2+}$-charged column (Fig. 4C and D). GST protein was not retained by any of the metal columns (Fig. 4C). These results support a role for the hydrophilic C-terminal part of $\mathrm{NrsD}$ as a metal binding domain. Our data suggest that this domain has a low specificity for metal binding, which has been previously shown for histidine-rich proteins (58). Histidine-rich domains have been found in UreE, HypB, and CooJ, which are small soluble proteins that are involved in processing $\mathrm{Ni}^{2+}$ for urease and hydrogenases $(30,42,58)$. Interestingly, it has been shown that a truncated version of UreE which lacks the histidine-rich C-terminal region still binds $\mathrm{Ni}^{2+}$ and functions in vivo (6). Organisms with high-affinity uptake systems for $\mathrm{Ni}^{2+}$ have UreE-like proteins lacking the histidine-rich region (26), leading to the suggestion that the histidine-rich region functions to store $\mathrm{Ni}^{2+}$ ions (6). One possibility is that the histidine-rich C-terminal region of $\mathrm{NrsD}$ is used to store metal ions that are going to be transported. 
A

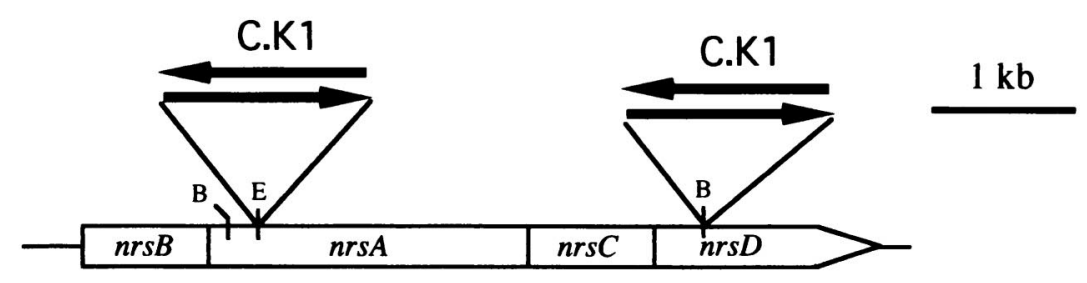

B

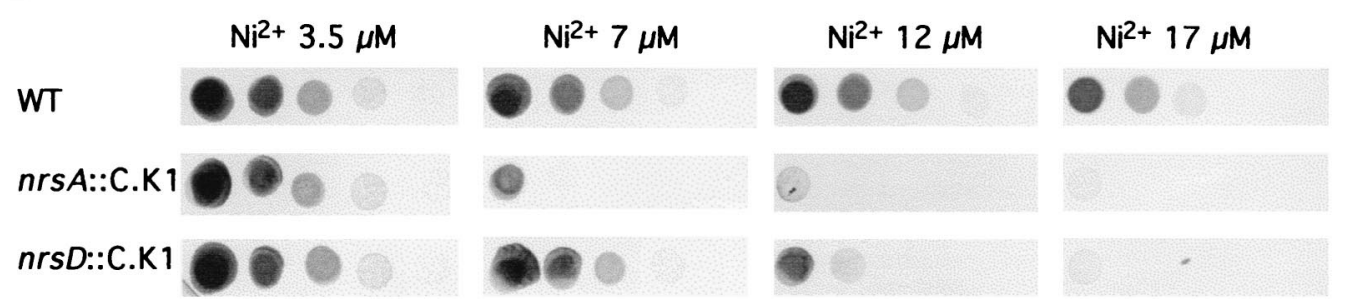

FIG 3. $\mathrm{Ni}^{2+}$ tolerance of Synechocystis $n r s A \because \mathrm{C} . \mathrm{K} 1$ and $n r s D * \mathrm{C} . \mathrm{K} 1$ mutants. (A) Schematic representation of the $n r s$ genomic region in the wild-type strain and sites of insertion of the C.K1 cassette in the nrs A::C.K1 and nrsD::C.K1 mutants. The C.K1 cassette was inserted in both orientations, as indicated. B, BstEII; E, EcoRI. (B) $\mathrm{Ni}^{2+}$ tolerance of wild-type Synechocystis sp. strain PCC 6803 (WT) and Synechocystis nrsA::C.K1 and nrsD::C.K1 mutants. Mutants with the C.K1 cassette in the same orientation as the nrs genes are shown. Tenfold serial dilutions were spotted on $\mathrm{BG}_{11 \mathrm{C}}$ plates, supplemented with the indicated concentrations of $\mathrm{NiSO}_{4}$, and photographed after 10 days of growth.

A MerR-related transcription activator involved in $\mathbf{C o}^{2+}$ sensing. The nrs operon was induced by $\mathrm{Co}^{2+}$ (Fig. 1), suggesting that it might be involved in $\mathrm{Co}^{2+}$ tolerance. However, nrsD::C.K1 and nrs $A::$ C.K1 mutant cells did not show reduced tolerance for $\mathrm{Co}^{2+}$. These data together with the pattern of hybridization obtained with probe $\mathbf{d}$ in Fig. 1 suggested the existence of an alternative system involved in $\mathrm{Co}^{2+}$ homeostasis. The ORF slr0797 product shares clear homology with cat-
$\mathbf{A}$

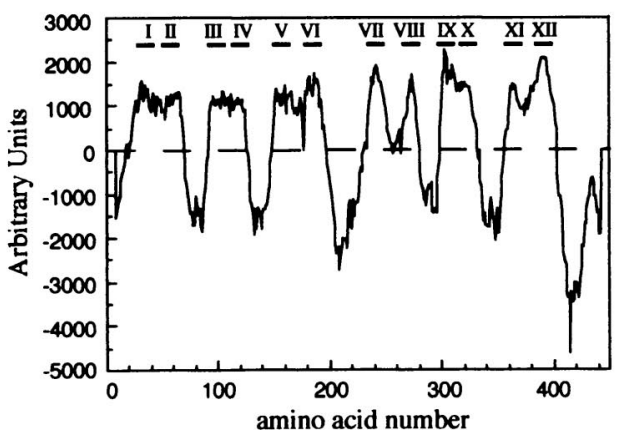

C

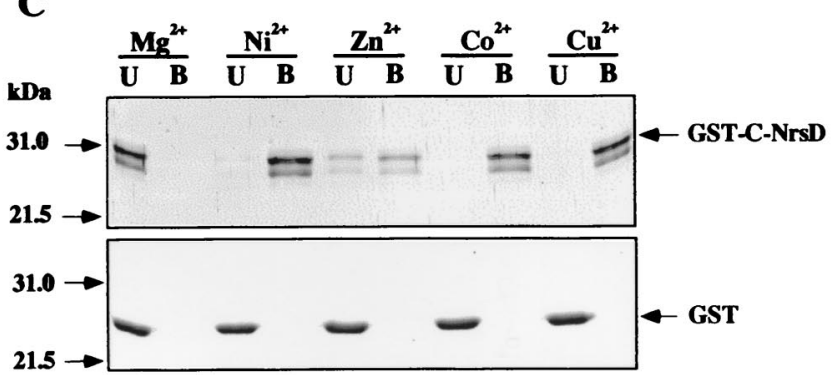

$\mathbf{B}$

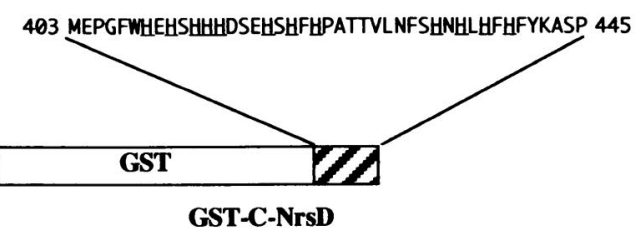

D

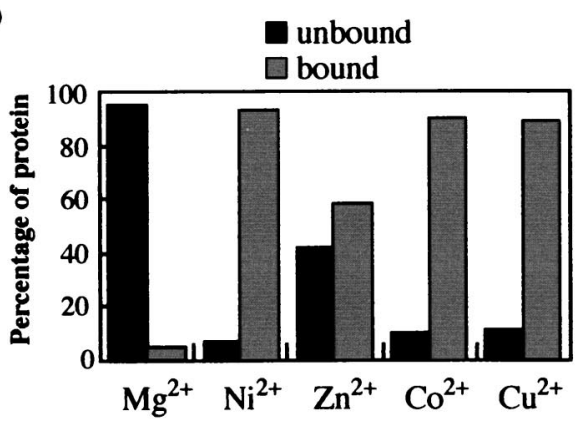

FIG. 4. Analysis of NrsD protein. (A) Prediction of NrsD membrane-spanning regions. The probability of transmembrane regions was calculated by using the TM-pred program (18). (B) Schematic representation of GST-C-NrsD protein. The chimeric protein comprises amino acids 403 to 445 of NrsD (C-terminal domain, C-NrsD) fused to GST. Histidine residues are underlined. (C and D) The interaction of GST or GST-C-NrsD proteins with metals was analyzed by metal chromatography. His-bind resin columns were loaded with either $\mathrm{Mg}^{2+}, \mathrm{Ni}^{2+}, \mathrm{Zn}^{2+}, \mathrm{Co}^{2+}$, or $\mathrm{Cu}^{2+}$. About $30 \mu \mathrm{g}$ of purified GST-C-NrsD or GST was applied to the columns. Unbound (lanes U) (flowthrough) and bound (lanes B) (imidazole-eluted) fractions were analyzed by SDS-PAGE (12\% polyacrylamide) and Coomassie blue staining (C), and protein was quantified by the method of Bradford (5). (D). 


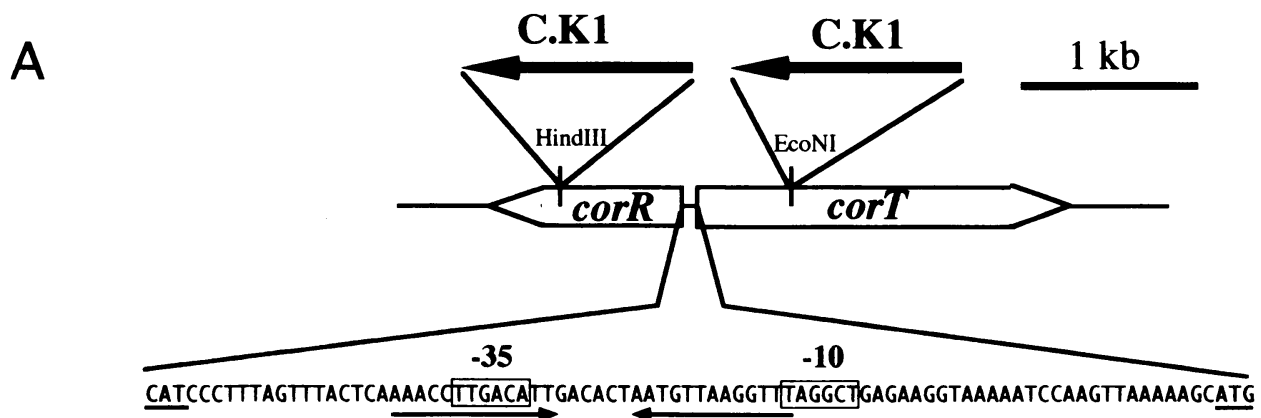

B

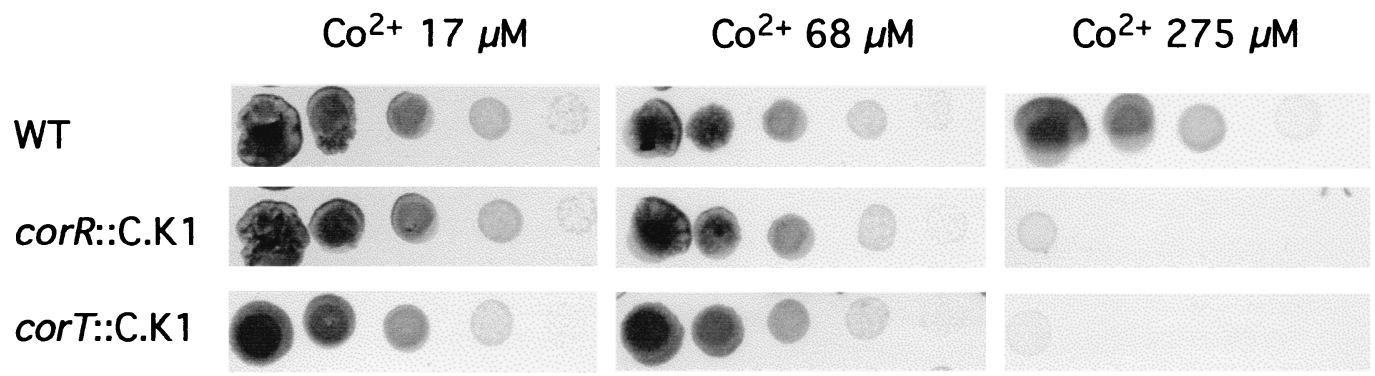

FIG. 5. $\mathrm{Co}^{2+}$ tolerance of Synechocystis corT::C.K1 and corR::C.K1 mutants. (A) Schematic representation of the corR-corT genomic region. The sites of insertion of the C.K1 cassette in the $\operatorname{cor} T:: \mathrm{C} . \mathrm{K} 1$ and $\operatorname{corR}:: \mathrm{C} . \mathrm{K} 1$ mutants are shown. The nucleotide sequence of the $\operatorname{corR}$-corT intergenic region is also shown. Putative -10 and -35 boxes of the $\operatorname{cor} T$ promoter are boxed. A hyphenated inverted repeat (13-6-13) with one mismatch is marked with arrows. The start codons of $\operatorname{cor} T$ and $\operatorname{corR}$ are underlined. (B) $\mathrm{Co}^{2+}$ tolerance of wild-type Synechocystis sp. strain PCC 6803 (WT) and the corT::C.K1 and corR::C.K1 mutants. Tenfold serial dilutions were spotted on BG11C plates, supplemented with the indicated concentrations of $\mathrm{CoCl}_{2}$, and photographed after 10 days of growth.

ion-transporting P-type ATPases, such as the bacterial $\mathrm{Cd}^{2+}$ transporter $\mathrm{CadA}$ or the bacterial $\mathrm{Cu}^{2+}$ transporters $\mathrm{CtaA}$, PacS, CopA, and CopB (reviewed in reference 40). The closest homolog to the slr0797 product is ZiaA (slr0798), the $\mathrm{Zn}^{2+}$ dependent ATPase from Synechocystis sp. strain PCC 6803 (51), encoded by another gene of the cluster (Fig. 1A). Induction of slr0797 mRNA by $\mathrm{Co}^{2+}$ suggested that the slr0797 gene product might be involved in the homeostasis of this cation. This hypothesis was investigated by interrupting the slr0797 gene with a kanamycin resistance cassette (Fig. $5 \mathrm{~A}$ ) and testing the metal tolerance of the resulting mutant strain. Growth of slr0797::C.K1 mutants in $\mathrm{Zn}^{2+}-, \mathrm{Ni}^{2+}$, and $\mathrm{Co}^{2+}$-supplemented BG11C medium was examined. Normal growth was observed in $\mathrm{Zn}^{2+}$ - or $\mathrm{Ni}^{2+}$-containing medium (data not shown); however, a reduced tolerance to $\mathrm{Co}^{2+}$ was detected (Fig. 5B). This result indicates that the slr0797 ORF is involved in $\mathrm{Co}^{2+}$ tolerance. Since the slr0797 product shows clear homology with cation-transporting P-type ATPases, our data point to the slr0797 product as a $\mathrm{Co}^{2+}$ efflux pump. Based on this role in $\mathrm{Co}^{2+}$ transport, the slr0797 ORF was designed corT (for cobalt response transporter). The fact that corT is also weakly induced by $\mathrm{Zn}^{2+}$ suggests that this ATPase might be involved in $\mathrm{Zn}^{2+}$ tolerance. However, the corT mutant cells did not show reduced $\mathrm{Zn}^{2+}$ tolerance. A probable reason for this result is the existence of a $\mathrm{Zn}^{2+}$-specific ATPase, $\mathrm{ZiaA}$, able to control $\mathrm{Zn}^{2+}$ homeostasis (51). Another possibility is that $\mathrm{Zn}^{2+}$ is a gratuitous inducer for $\operatorname{cor} T$ gene expression.

At $81 \mathrm{bp}$ upstream of $\operatorname{cor} T$ and in the opposite orientation appears the ORF sll0794 (Fig. 1A). Sequence analysis revealed that sll0794 encodes a 370-amino-acid protein with two different domains. Thus, the amino-terminal domain (amino acids 10 to 70 ) shares strong similarity with the DNA binding do- mains of components of the MerR family of DNA binding proteins (50). In contrast, the $\mathrm{C}$-terminal region, from amino acid 170 to 358 , shows significant similarity (30\% identity in 180 amino acids) to precorrin isomerases (precorrin-8x methylmutases) from different origins (Fig. 6) $(10,52)$. Precorrin isomerase, the product of the gene $c o b H$, is involved in the

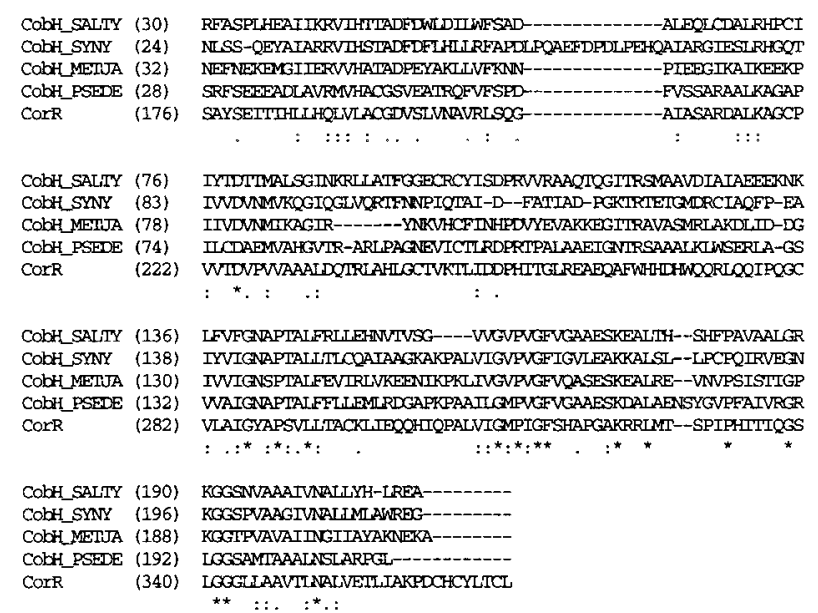

FIG. 6. Sequence alignment of the CorR C-terminal domain with precorrin isomerase $(\mathrm{CobH})$ amino acid sequences from different origins. COBH SALTY, CobH from Salmonella enterica serovar Typhimurium; COBH_SYNY, CobH from Synechocystis sp. strain PCC 6803; COBH METJA, CobH from Methanococcus jannaschii; COBH PSEDE, $\mathrm{CobH}$ from $\bar{P}$ seudomonas denitrificans. Identical amino acids are marked with asterisks; conservative changes are marked with colons or dots (as defined by CLUSTAL X [53]). 


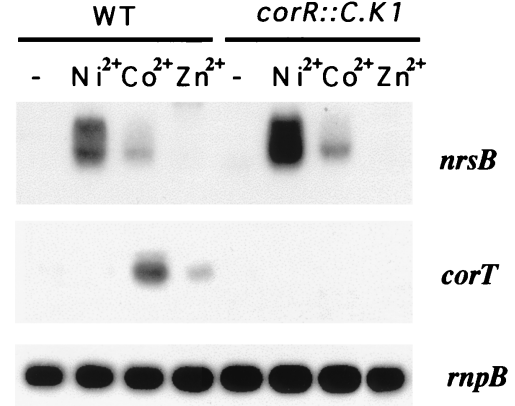

FIG. 7. Loss of $\operatorname{cor} T$ induction in the corR::C.K1 mutant. Total RNA was isolated from mid-log-phase wild-type Synechocystis sp. strain PCC 6803 (WT) or from Synechocystis corR::C.K1 mutant cells exposed for $1 \mathrm{~h}$ to a $15 \mu \mathrm{M}$ concentration of the indicated metal ions. Control cells were not exposed to added metals (-). RNA was isolated, processed, and hybridized as described for Fig. 1, using an $n r s B$ or a $\operatorname{cor} T$ gene probe (probes a and d, respectively [Fig. 1A]). The filters were stripped and rehybridized with an $r p B$ gene probe as a control.

biosynthetic pathway of cobalamin. In cobalamin a cobalt atom is held by coordination bonds to the nitrogen atoms of the four pyrrole rings of corrin (reviewed in reference 44). Precorrin isomerase catalyzes the synthesis of hydrogenobyrinic acid from precorrin-8x by transferring a methyl group from $\mathrm{C}-11$ to $\mathrm{C}$-12. It has been shown that precorrin isomerase is able to tightly bind hydrogenobyrinic acid, a class of corrinoid ring (52). It is also known that corrinoids are able to bind cobalt under certain conditions (54). The fact that the sll0794 gene product contains a domain homologous to precorrin isomerase and another domain involved in DNA binding suggested the attractive hypothesis that this protein was involved in transcriptional regulation mediated by $\mathrm{Co}^{2+}$. We have been unable to detect the corR mRNA (Fig. 1B), indicating that CorR is expressed at very low levels, consistent with its possible regulatory role. Because of this regulatory role, sl10794 was named corR (for cobalt response regulator).

In order to verify this hypothesis, the $\operatorname{cor} R$ gene was interrupted by a kanamycin resistance cassette (Fig. 5A). The resulting Synechocystis mutant strain (corR::C.K1) was viable and grew normally in BG11C medium. Growth of the corR::C.K1 mutant strain was also examined in $\mathrm{Zn}^{2+}-, \mathrm{Ni}^{2+}$, and $\mathrm{Co}^{2+}$ supplemented BG11C medium. Normal growth was observed in $\mathrm{Zn}^{2+}$ - or $\mathrm{Ni}^{2+}$-containing medium (data not shown); however, a reduced growth in $\mathrm{Co}^{2+}$-containing medium was observed (Fig. 5B). These data, together with the results of the sequence analysis commented on above, suggested a role of CorR as a positive regulator of a $\mathrm{Co}^{2+}$ response element. One obvious candidate to be regulated by CorR was the $\operatorname{cor} T$ gene. Expression of different transcriptional units of the cluster was analyzed in the corR::C.K1 mutant. Northern blot experiments showed that $\mathrm{Co}^{2+}$ - and $\mathrm{Zn}^{2+}$-dependent induction of the corT mRNA was absent in corR::C.K1 cells (Fig. 7). In contrast, $\mathrm{Ni}^{2+}$ - or $\mathrm{Co}^{2+}$-dependent induction of the nrs operon was not affected in this strain (Fig. 7). These data indicate that CorR is a transcriptional activator of $\operatorname{cor} T$ expression, which responds both to $\mathrm{Co}^{2+}$ and, to a lesser extent, to $\mathrm{Zn}^{2+}$. Our data also indicate that the low $\mathrm{Co}^{2+}$ tolerance of the corR::C.K1 strain is a consequence of the absence of $\operatorname{cor} T$ induction.

Promoters dependent on MerR-like proteins have an unusual structure $(2,50)$. Unlike regular sigma-70-dependent prokaryotic promoters, in which the -35 and -10 consensus elements are separated by 16- to 18 -bp-long spacers, the promoters regulated by MerR-type proteins have 19 - to 20 -bplong spacers. In typical MerR-like-dependent promoters this spacer region contains long inverted-repeat sequences which are the DNA binding sites for the MerR-like proteins. Sequence analysis of the $\operatorname{cor} R$ - $\operatorname{cor} T$ intergenic region revealed a putative MerR-type promoter with a 20-bp spacer and a 13bp-13-bp inverted repeat in the form AAACCTTGACATT$\mathrm{N}_{6}$-AATGTTAAGGTTT (Fig. 5A). Our present hypothesis is that this inverted repeat is the DNA target for CorR, which in the presence of $\mathrm{Co}^{2+}$ is able to promote transcriptional activation of $\operatorname{cor} T$. While this article was under review Rutherford et al. reported experiments that confirm that CorR binds to the corR-corT intergenic region (45). How is CorR able to sense $\mathrm{Co}^{2+}$ ? One obvious possibility is that the precorrin isomerasehomologous domain of CorR binds some class of corrinoid ring. $\mathrm{Co}^{2+}$ binding to the corrinoid ring would provoke a change in the transcriptional function of the protein. However, Rutherford et al. show data suggesting that the metal and the corrinoid ring bind to different domains (45). Their model predicts that the binding of hydrogenobyrinic acid to the precorrin isomerase domain of CorR prevents cobalt-mediated conformational change required for activation. The protein CorR is an interesting example of how an enzymatic protein domain (precorrin isomerase) has been adapted during evolution to a sensing and regulatory function.

In conclusion, we have described the existence in Synechocystis sp. strain PCC 6803 of a gene cluster composed of nine ORFs involved in heavy-metal tolerance. While five of the gene products seem to carry out functions related to metal export, two other genes encode proteins involved in metal sensing and regulation. The remaining two proteins encoded by the cluster show no clear homologs in the databases, and their role in metal resistance is an open question. Finally, how and why nine genes with related functions have been clustered in a region of the Synechocystis sp. strain PCC 6803 genome are interesting questions that remain to be addressed.

\section{ACKNOWLEDGMENTS}

We thank the Kazusa DNA Research Institute and S. Tabata for providing CS1377 cosmid DNA. We are grateful to E. Santero for critical reading of the manuscript.

M. García-Domínguez was the recipient of a fellowship from the Spanish Ministerio de Educación y Cultura. This work was supported by grant PB97-0732 from DGESIC and by Junta de Andalucía (group CV1-0112).

\section{REFERENCES}

1. Altschul, S. F., T. L. Madden, A. A. Schaffer, J. Zhang, Z. Zhang, W. Miller, and D. J. Lipman. 1997. Gapped BLAST and PSI-BLAST: a new generation of protein database search programs. Nucleic Acids Res. 25:3389-3402.

2. Ansari, A. Z., J. E. Bradner, and T. V. O'Halloran. 1995. DNA-bend modulation in a repressor-to-activator switching mechanism. Nature 374:371375.

3. Beard, S. J., R. Hashim, J. Membrillo-Hernandez, M. N. Hughes, and R. K. Poole. 1997. Zinc(II) tolerance in Escherichia coli K-12: evidence that the $z n t A$ gene (o732) encodes a cation transport ATPase. Mol. Microbiol. 25: 883-891.

4. Beard, S. J., M. N. Hughes, and R. K. Poole. 1995. Inhibition of the cytochrome $b d$-terminated NADH oxidase system in Escherichia coli K-12 by divalent metal cations. FEMS Microbiol. Lett. 131:205-210.

5. Bradford, M. M. 1976. A rapid and sensitive method for quantitation of microgram quantities of protein utilizing the principle of protein-dye binding. Anal. Biochem. 72:248-254.

6. Brayman, T. G., and R. P. Hausinger. 1996. Purification, characterization, and functional analysis of a truncated Klebsiella aerogenes UreE urease accessory protein lacking the histidine-rich carboxyl terminus. J. Bacteriol. 178:5410-5416.

7. Brocklehurst, K. R., J. L. Hobman, B. Lawley, L. Blank, S. J. Marshall, N. L. Brown, and A. P. Morby. 1999. ZntR is a Zn(II)-responsive MerR-like transcriptional regulator of $z n t A$ in Escherichia coli. Mol. Microbiol. 31: 893-902.

8. Cai, Y., and C. P. Wolk. 1990. Use of a conditionally lethal gene in Anabaena sp. strain PCC 7120 to select for double recombinants and to entrap insertion 
sequences. J. Bacteriol. 172:3138-3145.

9. Cook, W. J., S. R. Kar, K. B. Taylor, and L. M. Hall. 1998. Crystal structure of the cyanobacterial metallothionein repressor SmtB: a model for metalloregulatory proteins. J. Mol. Biol. 275:337-346.

10. Crouzet, J., B. Cameron, L. Cauchois, S. Rigault, M. C. Rouyez, F. Blanche, D. Thibaut, and L. Debussche. 1990. Genetic and sequence analysis of an 8.7-kilobase Pseudomonas denitrificans fragment carrying eight genes involved in transformation of precorrin-2 to cobyrinic acid. J. Bacteriol. 172: 5980-5990.

11. De Pina, K., V. Desjardin, M. A. Mandrand-Berthelot, G. Giordano, and L. F. Wu. 1999. Isolation and characterization of the nikR gene encoding a nickel-responsive regulator in Escherichia coli. J. Bacteriol. 181:670-674.

12. Eitinger, T., and B. Friedrich. 1991. Cloning, nucleotide sequence, and heterologous expression of a high-affinity nickel transport gene from Alcaligenes eutrophus. J. Biol. Chem. 266:3222-3227.

13. Eitinger, T., L. Wolfram, O. Degen, and C. Anthon. 1997. A Ni2+ binding motif is the basis of high affinity transport of the Alcaligenes eutrophus nickel permease. J. Biol. Chem. 272:17139-17144.

14. Elhai, J., and C. P. Wolk. 1988. A versatile class of positive-selection vectors based on the nonviability of palindrome-containing plasmids that allows cloning into long polylinkers. Gene 68:119-138.

15. Ferino, F., and F. Chauvat. 1989. A promoter-probe vector-host system for the cyanobacterium, Synechocystis PCC6803. Gene 84:257-266.

16. Fu, C., S. Javedan, F. Moshiri, and R. J. Maier. 1994. Bacterial genes involved in incorporation of nickel into a hydrogenase enzyme. Proc. Natl. Acad. Sci. USA 91:5099-5103.

17. García-Domínguez, M., and F. J. Florencio. 1997. Nitrogen availability and electron transport control the expression of $g \ln B$ gene (encoding PII protein) in the cyanobacterium Synechocystis sp. PCC 6803. Plant Mol. Biol. 35: 723-734.

18. Hofmann, K., and W. Stoffel. 1993. TMbase-a database of membrane spanning protein segments. Biol. Chem. Hoppe-Seyler 347:166.

19. Huckle, J. W., A. P. Morby, J. S. Turner, and N. J. Robinson. 1993. Isolation of a prokaryotic metallothionein locus and analysis of transcriptional control by trace metal ions. Mol. Microbiol. 7:177-187.

20. Kanamaru, K., S. Kashiwagi, and T. Mizuno. 1994. A copper-transporting P-type ATPase found in the thylakoid membrane of the cyanobacterium Synechococcus species PCC7942. Mol. Microbiol. 13:369-377.

21. Kaneko, T., S. Sato, H. Kotani, A. Tanaka, E. Asamizu, Y. Nakamura, N. Miyajima, M. Hirosawa, M. Sugiura, S. Sasamoto, T. Kimura, T. Hosouchi, A. Matsuno, A. Muraki, N. Nakazaki, K. Naruo, S. Okumura, S. Shimpo, C. Takeuchi, T. Wada, A. Watanabe, M. Yamada, M. Yasuda, and S. Tabata. 1996. Sequence analysis of the genome of the unicellular cyanobacterium Synechocystis sp. strain PCC6803. II. Sequence determination of the entire genome and assignment of potential protein-coding regions. DNA Res. 3: 109-136.

22. Kleiner, D. 1978. Inhibition of the respiratory system in Azotobacter vinelandii by divalent transition metal ions. FEBS Lett. 96:364-366.

23. Komeda, H., M. Kobayashi, and S. Shimizu. 1997. A novel transporter involved in cobalt uptake. Proc. Natl. Acad. Sci. USA 94:36-41.

24. Laemmli, U. K. 1970. Cleavage of structural proteins during the assembly of the head of bacteriophage T4. Nature 227:680-685.

25. Liesegang, H., K. Lemke, R. A. Siddiqui, and H. G. Schlegel. 1993. Characterization of the inducible nickel and cobalt resistance determinant $\mathrm{cnr}$ from pMOL28 of Alcaligenes eutrophus CH34. J. Bacteriol. 175:767-778.

26. Lutz, S., A. Jacobi, V. Schlensog, R. Bohm, G. Sawyers, and A. Bock. 1991. Molecular characterization of an operon (hyp) necessary for the activity of the three hydrogenase isoenzymes in Escherichia coli. Mol. Microbiol. 5: 123-135.

27. Maeda, M., M. Hidaka, A. Nakamura, H. Masaki, and T. Uozumi. 1994. Cloning, sequencing, and expression of thermophilic Bacillus sp. strain TB-90 urease gene complex in Escherichia coli. J. Bacteriol. 176:432-442.

28. Mallick, N., and L. C. Rai. 1992. Metal induced inhibition of photosynthesis, photosynthetic electron transport chain and ATP content of Anabaena doliolum and Chlorella vulgaris: interaction with exogenous ATP. Biomed. Environ. Sci. 5:241-250.

29. Mobley, H. L., R. M. Garner, and P. Bauerfeind. 1995. Helicobacter pylori nickel-transport gene nixA: synthesis of catalytically active urease in Escherichia coli independent of growth conditions. Mol. Microbiol. 16:97-109.

30. Mulrooney, S. B., and R. P. Hausinger. 1990. Sequence of the Klebsiella aerogenes urease genes and evidence for accessory proteins facilitating nickel incorporation. J. Bacteriol. 172:5837-5843.

31. Navarro, C., L. F. Wu, and M. A. Mandrand-Berthelot. 1993. The nik operon of Escherichia coli encodes a periplasmic binding-protein-dependent transport system for nickel. Mol. Microbiol. 9:1181-1191.

32. Nies, D. H., A. Nies, L. Chu, and S. Silver. 1989. Expression and nucleotide sequence of a plasmid-determined divalent cation efflux system from Alcali- genes eutrophus. Proc. Natl. Acad. Sci. USA 86:7351-7355.

33. Nies, D. H., and S. Silver. 1989. Metal ion uptake by a plasmid-free metalsensitive Alcaligenes eutrophus strain. J. Bacteriol. 171:4073-4075.

34. Nucifora, G., L. Chu, T. K. Misra, and S. Silver. 1989. Cadmium resistance from Staphylococcus aureus plasmid pI258 cadA gene results from a cadmium-efflux ATPase. Proc. Natl. Acad. Sci. USA 86:3544-3548.

35. Odermatt, A., H. Suter, R. Krapf, and M. Solioz. 1993. Primary structure of two P-type ATPases involved in copper homeostasis in Enterococcus hirae. J. Biol. Chem. 268:12775-12779.

36. Pao, S. S., I. T. Paulsen, and M. H. Saier, Jr. 1998. Major facilitator superfamily. Microbiol. Mol. Biol. Rev. 62:1-34.

37. Patzer, S. I., and K. Hantke. 1998. The ZnuABC high-affinity zinc uptake system and its regulator Zur in Escherichia coli. Mol. Microbiol. 28:11991210 .

38. Phung, L. T., G. Ajlani, and R. Haselkorn. 1994. P-type ATPase from the cyanobacterium Synechococcus 7942 related to the human Menkes and Wilson disease gene products. Proc. Natl. Acad. Sci. USA 91:9651-9654.

39. Rai, P. K., N. Mallick, and L. C. Rai. 1994. Effect of $\mathrm{Cu}$ and $\mathrm{Ni}$ on growth, mineral uptake, photosynthesis and enzyme activities of Chlorella vulgaris at different $\mathrm{pH}$ values. Biomed. Environ. Sci. 7:56-67.

40. Rensing, C., M. Ghosh, and B. P. Rosen. 1999. Families of soft-metal-iontransporting ATPases. J. Bacteriol. 181:5891-5897.

41. Rensing, C., T. Pribyl, and D. H. Nies. 1997. New functions for the three subunits of the CzcCBA cation-proton antiporter. J. Bacteriol. 179:68716879

42. Rey, L., J. Imperial, J. M. Palacios, and T. Ruiz-Argueso. 1994. Purification of Rhizobium leguminosarum HypB, a nickel-binding protein required for hydrogenase synthesis. J. Bacteriol. 176:6066-6073.

43. Rippka, R., J. Deruelles, J. B. Waterbury, M. Herdman, and R. Y. Stanier. 1979. Genetics assignments, strain histories and properties of pure cultures of cyanobacteria. J. Gen. Microbiol. 111:1-61.

44. Roth, J. R., J. G. Lawrence, and T. A. Bobik. 1996. Cobalamin (coenzyme B12): synthesis and biological significance. Annu. Rev. Microbiol. 50:137181.

45. Rutherford, J. C., J. S. Cavet, and N. J. Robinson. 1999. Cobalt-dependent transcriptional switching by a dual-effector MerR-like protein regulates a cobalt-exporting variant CPx-type ATPase. J. Biol. Chem. 274:25827-25832.

46. Sambrook, J., E. F. Fritsch, and T. Maniatis. 1989. Molecular cloning: a laboratory manual, 2nd ed. Cold Spring Harbor Laboratory Press, Cold Spring Harbor, N.Y.

47. Schmidt, T., and H. G. Schlegel. 1994. Combined nickel-cobalt-cadmium resistance encoded by the ncc locus of Alcaligenes xylosoxidans 31A. J. Bacteriol. 176:7045-7054.

48. Silver, S., and L. T. Phung. 1996. Bacterial heavy metal resistance: new surprises. Annu. Rev. Microbiol. 50:753-789.

49. Singh, V. K., A. Xiong, T. R. Usgaard, S. Chakrabarti, R. Deora, T. Misra, and R. K. Jayaswal. 1999. ZntR is an autoregulatory protein and negatively regulates the chromosomal zinc resistance operon znt of Staphylococcus aureus. Mol. Microbiol. 33:200-207.

50. Summers, A. O. 1992. Untwist and shout: a heavy metal-responsive transcriptional regulator. J. Bacteriol. 174:3097-3101.

51. Thelwell, C., N. J. Robinson, and J. S. Turner-Cavet. 1998. An SmtB-like repressor from Synechocystis PCC 6803 regulates a zinc exporter. Proc. Natl. Acad. Sci. USA 95:10728-10733.

52. Thibaut, D., M. Couder, A. Famechon, L. Debussche, B. Cameron, J. Crouzet, and F. Blanche. 1992. The final step in the biosynthesis of hydrogenobyrinic acid is catalyzed by the $c o b H$ gene product with precorrin-8x as the substrate. J. Bacteriol. 174:1043-1049.

53. Thompson, J. D., T. J. Gibson, F. Plewniak, F. Jeanmougin, and D. G. Higgins. 1997. The CLUSTAL X windows interface: flexible strategies for multiple sequence alignment aided by quality analysis tolls. Nucleic Acids Res. 25:4876-4882.

54. Toohey, J. I. 1965. A vitamin B12 compound containing no cobalt. Proc. Natl. Acad. Sci. USA 54:934-942.

55. van der Lelie, D., T. Schwuchow, U. Schwidetzky, S. Wuertz, W. Baeyens, M. Mergeay, and D. H. Nies. 1997. Two-component regulatory system involved in transcriptional control of heavy-metal homoeostasis in Alcaligenes eutrophus. Mol. Microbiol. 23:493-503.

56. Vioque, A. 1992. Analysis of the gene encoding the RNA subunits of ribonuclease P from cyanobacteria. Nucleic Acids Res. 20:6331-6337.

57. von Heijne, G. 1992. Membrane protein structure prediction, hydrophobicity analysis and the positive-inside rule. J. Mol. Biol. 225:487-494.

58. Watt, R. K., and P. W. Ludden. 1998. The identification, purification, and characterization of $\mathrm{CooJ}$. A nickel-binding protein that is co-regulated with the Ni-containing $\mathrm{CO}$ dehydrogenase from Rhodospirillum rubrum. J. Biol. Chem. 273:10019-10025. 